
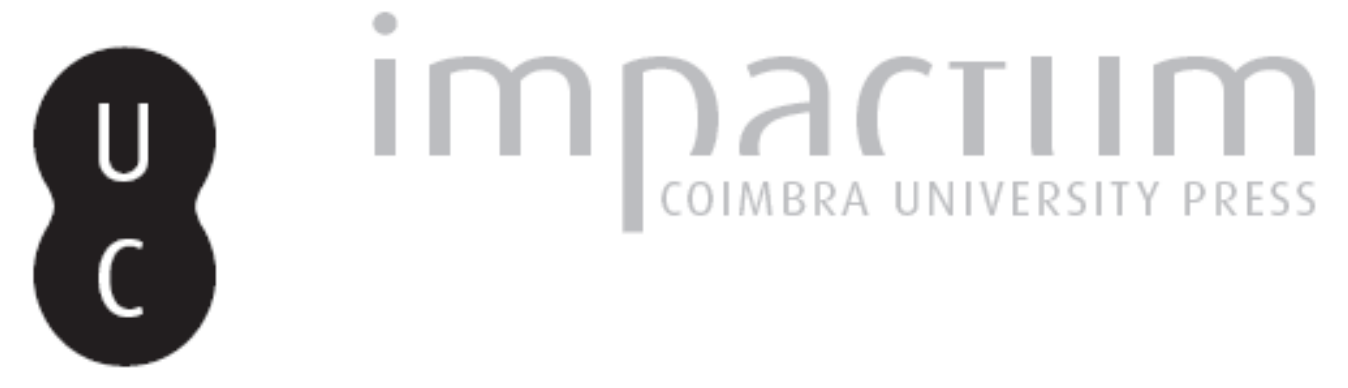

\title{
Crise e catástrofe na novela A descoberta da salsicha com caril de Uwe Timm: os alemães na derrocada do Terceiro Reich
}

\author{
Autor(es): $\quad$ Madeira, Rogério Paulo
}

Publicado por: Faculdade de Letras da Universidade de Coimbra

URL

persistente:

URI:http://hdl.handle.net/10316.2/32285

DOI:

DOI:http://dx.doi.org/10.14195/0870-4112_10_7

Accessed : $\quad$ 26-Apr-2023 03:27:10

A navegação consulta e descarregamento dos títulos inseridos nas Bibliotecas Digitais UC Digitalis, UC Pombalina e UC Impactum, pressupõem a aceitação plena e sem reservas dos Termos e Condições de Uso destas Bibliotecas Digitais, disponíveis em https://digitalis.uc.pt/pt-pt/termos.

Conforme exposto nos referidos Termos e Condições de Uso, o descarregamento de títulos de acesso restrito requer uma licença válida de autorização devendo o utilizador aceder ao(s) documento(s) a partir de um endereço de IP da instituição detentora da supramencionada licença.

Ao utilizador é apenas permitido o descarregamento para uso pessoal, pelo que o emprego do(s) título(s) descarregado(s) para outro fim, designadamente comercial, carece de autorização do respetivo autor ou editor da obra.

Na medida em que todas as obras da UC Digitalis se encontram protegidas pelo Código do Direito de Autor e Direitos Conexos e demais legislação aplicável, toda a cópia, parcial ou total, deste documento, nos casos em que é legalmente admitida, deverá conter ou fazer-se acompanhar por este aviso.

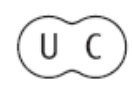



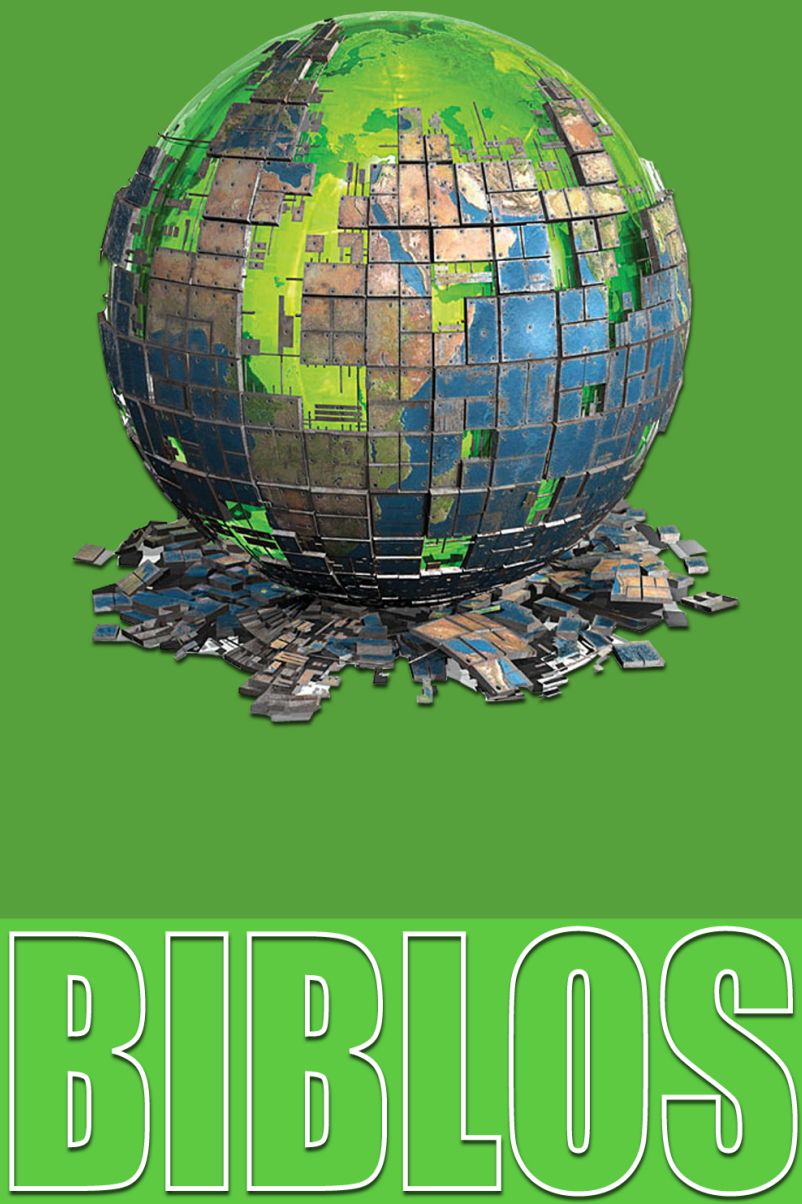

$\frac{\text { REVISTA DA FACULDADE DE LETRAS }}{\text { UNIVERSIDADE DE COIMBRA }}$ 
Biblos, n. s. X (2012) $\ldots-\ldots$

Rogério Paulo Madeira

Faculdade de Letras da Universidade de Coimbra

\title{
CRISE E CATÁSTROFE NA NOVELA \\ A DESCOBERTA DA SALSICHA COM CARIL DE UWE TIMM: OS ALEMÃES NA DERROCADA DO TERCEIRO REICH*
}

\begin{abstract}
Resumo
O presente artigo debruça-se sobre a novela histórica A descoberta da salsicha com caril (1993), de Uwe Timm, cuja ação se desenvolve em torno de uma história de amor proibido entre Lena Brücker, uma figura feminina representativa do alemão comum, e um desertor da Marinha que se refugia na cidade de Hamburgo durante a fase final da maior crise e catástrofe para a humanidade no decurso do século XX: a Segunda Guerra Mundial. Após um breve enquadramento histórico-literário da obra em apreço, a análise incide, especialmente, no modo crítico mas diferenciado como o autor retrata os Alemães no momento da derrocada do Terceiro Reich, com destaque para algumas figuras de cúmplices, culpados e vítimas das atrocidades, sem descurar várias formas de resistência contra o regime nacional-socialista.
\end{abstract}

Palavras-Chave: Literatura e História; memória; República de Berlim; Segunda Guerra Mundial; nacional-socialismo; Holocausto; resistência no III Reich.

\begin{abstract}
This article deals with Uwe Timm's historical «novella» The Invention of Curried Sausage (1993), whose plot structure is based on a story of forbidden
\end{abstract}

* O presente artigo constitui uma versão refundida da conferência intitulada "Uwe Timm: A descoberta da salsicha com caril [Die Entdeckung der Currywurst] (1993). Um novo olhar sobre os Alemães na derrocada do III Reich e no imediato pós-guerra", apresentada a 19 de maio de 2011, na Faculdade de Letras da Universidade de Coimbra, no I Ciclo de Conferências dedicado a "Re-Leituras do Alemão", promovido pela Secção de Alemão do Departamento de Línguas, Literaturas e Culturas da mesma Faculdade, e insere-se no projeto de investigação "Relações Literárias e Culturais Luso-Alemãs. Estudos de Receção e de Hermenêutica Intercultural", coordenado pela Professora Doutora Maria Manuela Gouveia Delille, do Centro de Investigação em Estudos Germanísticos (CIEG), Unidade de I \& D financiada pela Fundação para a Ciência e a Tecnologia, no âmbito do Projeto Estratégico UI25 - 2011-2012 (PEst-OE/ELT/UI0025/2011). 
love between Lena Brücker, a female character that represents the common German, and a Navy deserter who hides in Hamburg during the end of the biggest human crisis and catastrophe in the $20^{\text {th }}$ century: the Second World War. After a brief historical and literary contextualization of the «novella», the analysis focuses especially on the critical but differentiated way the author represents the Germans at the collapse of the Third Reich with particular emphasis on some characters of accomplices, perpetrators, and victims of atrocities, and also on several forms of resistance against the nazi regime.

Keywords: Literature and History; memory; Republic of Berlin; World War II; nazism; Holocaust; resistance in the Third Reich. 


\section{O espetro do passado e a "viragem da memória" na literatura alemã}

A Segunda Guerra Mundial - que só no continente europeu custou 40 milhões de vidas humanas e, em maio de 1945, pôs fim à ditadura nacional-socialista e ao Holocausto, ${ }^{1}$ instaurando uma nova ordem - constitui uma das maiores crises e catástrofes da História da humanidade. De resto, desde o imediato pós-guerra, o maior conflito militar do século XX e o famigerado Terceiro Reich têm alimentado do ponto de vista temático um vasto número de obras de natureza historiográfica, cinematográfica e literária, entre outras, o qual voltou a aumentar após a queda do Muro de Berlim e a subsequente reunificação da Alemanha. A literatura de expressão alemã não se afigura de modo nenhum como exceção; pelo contrário, basta espreitar qualquer história ou manual de literatura alemã do século XX para comprovar que os primeiros anos da Alemanha reunificada iniciam um período histórico-literário particularmente produtivo e recetivo no que concerne a obras de ficção dedicadas ao capítulo mais negro da História alemã. ${ }^{2}$

A heterogeneidade formal e temática de tal período oscila entre os polos da continuidade e da mudança ${ }^{3}$ e permite distinguir alguns estilos e tendências mais persistentes, mas impossibilita, por enquanto, a atribuição de um conceito descritivo que reúna algum consenso, para além dos termos "pós-modernidade" ou "pós-modernismo", os quais estão longe de satisfazer a generalidade dos críticos e historiadores literários. ${ }^{4}$ Contudo, é interessante verificar que, na sequência da mudança política operada pela queda do Muro e pela reunificação, se assiste a uma "viragem da memória" dos Alemães ("Wende des

${ }^{1}$ Cf. Diether Raff, Deutsche Geschichte. Vom Alten Reich zum Vereinten Deutschland, München, Heyne, ${ }^{6} 1997,386$.

${ }^{2}$ Veja-se, p.ex., Jürgen Egyptien, Einführung in die deutschsprachige Literatur seit 1945, Darmstadt, Wissenschaftliche Buchgesellschaft, 2006, 7-13, 62-99, e Wilfried Barner (Hrsg.), Geschichte der deutschen Literatur von 1945 bis zur Gegenwart, 2., erw. Aufl., München, Beck, 2006, 925-1130.

${ }^{3}$ Cf. J. Egyptien, op. cit., 10s.

${ }^{4}$ A este respeito consulte-se, principalmente, ibid., 10s. e W. Barner, op. cit., 925-963. 
Erinnerns"), ${ }^{5}$ em grande medida ainda dominada por autores da primeira geração - como Günter Grass (n. 1927) ou Martin Walser (n. 1927) e da geração intermédia, também designada como geração de 68 , da qual fazem parte Peter Schneider (n. 1940), Peter Handke (n. 1942), Bernhard Schlink (n. 1944), W. G. Sebald (1944-2000) e Uwe Timm (n. 1940), mas também por alguns nomes da terceira geração, como Marcel Beyer (n. 1965) e Thomas Brussig (n. 1965), por exemplo.

Porventura mais libertos de velhos preceitos ideológicos, vários autores da chamada República de Berlim, herdeiros involuntários de um legado histórico-político particularmente pesado e sombrio, deixado por pais e/ou por avós que conviveram com a realidade do nacional-socialismo, começam a romper o silêncio imposto, ao longo de várias décadas, no âmbito restrito do espaço e do diálogo familiares, e a contornar o discurso politicamente correcto. E fazem-no, lançando um novo olhar - frequentemente provocatório - não apenas sobre o passado mais recente dos dois lados da fronteira da Alemanha dividida, mas também sobre as experiências ainda mais incómodas, relacionadas com a ditadura nacional-socialista, nomeadamente a questão das vítimas e dos culpados, e com a Segunda Guerra Mundial, aduzindo aspetos até então esquecidos ou omitidos no âmbito oficial dos discursos políticos, memorialistas e historiográficos. ${ }^{6}$ Reporto-me, fundamentalmente, ao sofrimento causado à população civil durante os ataques aéreos dos Aliados, lançados sobre as cidades alemãs na fase terminal da guerra e à fuga ou expulsão em massa das populações germânicas dos territórios de Leste, que haviam sido brutalmente usurpados pelo regime hitleriano na fase de expansão do Terceiro Reich e nos quais se havia instalado grande parte dos campos de concentração e de extermínio colocados ao serviço do Holocausto.?

${ }^{5}$ BarbaraBeßlichetal.(Hrsg.),WendedesErinnerns? Geschichtskonstruktionen in der deutschen Literatur nach 1989, Berlin, Schmidt, 2006, 7.

${ }^{6}$ Cf. especialmente Stuart Taberner/Karina Berger, "Introduction", in: S.T. \& K.B. (eds.), Germans as Victims in the Literary Fiction of the Berlin Republic, Rochester/New York, Camden House, 2009, 1-14.

${ }^{7}$ Cf. B. Beßlich et al., op . cit., 7-17; S. Taberner, "Introduction: literary fiction in the Berlin Republic", in: S. T. (ed.), Contemporary German Fiction. Writing in the Berlin Republic, New York, Cambridge University Press, 2007, 1-20; J. Egyptien, op. cit., 10ss., 76s. 


\section{A “construção literária de um acontecimento histórico" e o olhar do "etnógrafo empenhado" sobre a realidade quotidiana, ou a conceção estético-literária de Uwe Timm}

Um dos escritores da geração de 68 que mais atenção tem concedido ao tratamento literário da maior crise e catástrofe da História da Alemanha é Uwe Timm. O ficcionista nado e crescido em Hamburgo, certamente desconhecido do público leitor de língua portuguesa, é autor de uma obra diversificada que, além da prosa narrativa, abrange outras formas literárias, como o ensaio, a lírica, a peça radiofónica, a literatura infanto-juvenil e o argumento cinematográfico, contando mais de trinta títulos publicados. Sobretudo na sequência da publicação da novela Die Entdeckung der Currywurst [A descoberta da salsicha com caril], em 1993, ele tornou-se gradualmente num dos escritores alemães mais lidos na atualidade. A insistência na exploração do filão temático da História alemã, em estreita ligação com aspetos marcantes da sua própria biografia familiar, levou a que Martin Hielscher, crítico literário e biógrafo de Uwe Timm, considerasse o conjunto da sua obra como uma espécie de crónica literária da Alemanha do século XX, tendo contribuído de modo significativo para a obtenção de numerosos prémios literários. $^{8}$

Aliás, Timm confessou recentemente, numa das últimas edições das célebres "Frankfurter Poetikvorlesungen" [Conferências sobre Poética em Frankfurt], publicadas em 2009, sob o título Von Anfang und Ende. Über die Lesbarkeit der Welt [Do princípio e do fim. Sobre a legibilidade do mundo], a sua preferência pela prosa narrativa literária, reafirmando, a propósito do romance Morenga, uma conviç̧ão central que é igualmente válida para toda a sua ficção narrativa de temática histórica:

${ }^{8}$ Cf. Martin Hielscher, Uwe Timm, München, Deutscher Taschenbuch Verlag, 2007, 7s., 182. Para uma familiarização com os principais contornos da vida e obra de Uwe Timm, veja-se, p.ex., Hanjo Kesting/Axel Ruckaberle (2009), "Uwe Timm", in: Kritisches Lexikon zur deutschsprachigen Gegenwartsliteratur (KLG).Hrsg.v. HeinzLudwig Arnold, München, edition text + kritik, 1-23, e Thomas Kraft, "Uwe Timm", in: Lexikon der deutschsprachigen Gegenwartsliteratur seit 1945. Bd. 2: K-Z. Neu hrsg. v. Thomas Kraft, München, Nymphenburger, 2003, 1242-1245. 
[Morenga ist] eine literarische Konstruktion von einem geschichtlichen Ereignis und eine, in der, im Gegensatz zu der Geschichtswissenschaft, auch Zugochsen zu Wort kommen. Der Roman darf und kann alles, er kümmert sich nicht um Vorschriften und ästhetische Verbote, er ist die zeitgemäße vitale literarische Form, um über uns und das Verhältnis von Sprache und Wirklichkeit nachzudenken, und das auf eine lustvolle Weise. ${ }^{9}$

A ideia da liberdade poética no tratamento da matéria histórica não é, porém, uma convicção recente de Uwe Timm. Já antes da publicação da novela $A$ descoberta da salsicha com caril, nas suas primeiras conferências sobre poética, proferidas, em 1992, em Paderborn, e vindas a lume no ano seguinte com o título Erzählen und kein Ende. Versuche zu einer Ästhetik des Alltags [Sempre a narrar. Ensaios para uma estética do quotidiano], o autor estabelecera um programa estético-literário centrado na realidade quotidiana, do presente como do passado históricos, que denunciava uma filiação de base separatista, na qual ressoa o preceito aristotélico da arte literária. ${ }^{10} \mathrm{O}$ que Timm pretende criar é

[e]ine Geschichte, die nicht versucht, uns weiszumachen: So ist es gewesen, sondern: So könnte es gewesen sein. Das ist der wunderbare Konjunktiv.

9 "'[Morenga é] uma construção literária de um acontecimento histórico e uma construção, na qual, ao contrário da historiografia, até os bois de canga chegam a usar da palavra. O romance pode e é capaz de fazer tudo; não se preocupa com normas e proibições estéticas, e constitui a forma literária vital e adequada aos nossos dias para refletirmos sobre nós e sobre a relação entre linguagem e realidade, e isso de uma maneira divertida." (Uwe Timm, Von Anfang und Ende. Über die Lesbarkeit der Welt, Köln, Kiepenheuer \& Witsch, 2009, 118; itálicos meus). A tradução das citações das obras de Uwe Timm é da minha autoria.

${ }^{10}$ Recordo que a Poética (Prefácio de Maria Helena da Rocha Pereira. Tradução e notas de Ana Maria Valente, Lisboa, Fundação Calouste Gulbenkian, 2004, 54) de Aristóteles postula uma demarcação inequívoca das fronteiras entre o texto literário e o texto histórico, uma tese milenar que veio a conhecer inúmeros seguidores no campo da teoria e da praxis literárias. Para uma síntese da problemática das relações entre Literatura e História, nomeadamente no que respeita à controversa tese da convergência entre ficção histórica e historiografia, impulsionada pelo historiador norte-americano Hayden White (Metahistory, 1973), cf. e.o. R. P. Madeira, Ficção e História: a figura de Uriel da Costa na obra de Karl Gutzkow, Coimbra, MinervaCoimbra e Centro de Investigação em Estudos Germanísticos, 35-70). 
Wunderbar, weil er uns die Freiheit gibt, eine andere Wirklichkeit zu schaffen, und weil er das Diktat der Chronologie durchbricht. ${ }^{11}$

Efetivamente, o ideário que segue, pelo menos desde A descoberta da salsicha com caril, vincula o texto literário ao real, mas recusa a reprodução fiel, mimética do mundo, demarcando-se da literatura de caráter documental e com pretensões de cientificidade que fizera escola na década de 1960. Pelo contrário, por meio de uma conceção estético-literária que designa como "Ästhetik des Alltags" [estética do quotidiano], Timm visa em primeira instância desvelar "a verdade histórico-social oculta" (die verborgene geschichtlich-gesellschaftliche Wahrheit), ${ }^{12}$ leia-se: a história privada, ou não oficial, sobretudo dos mais desfavorecidos, dos desesperados que ocupam franjas mais baixas da sociedade, mas sem lhes pegar logo com a tenaz ideológica. ${ }^{13}$ Devido às suas potencialidades críticas e até subversivas, este tipo de literatura acaba por suscitar naturalmente, se não a rejeição, pelo menos a desconfiança do poder político instituído. ${ }^{14}$ Ora é isso mesmo que Uwe Timm pretende.

Atento à realidade do cidadão comum e sensível à voz do povo, o autor inspira-se muitas vezes em palavras, "objetos marcados" [gezeichnete Dinge], pequenas ações ou situações do dia-a-dia, aparentemente insignificantes, mas que contêm em si - ou vêm a adquirir, através do labor artístico do escritor, - um significado e um valor acrescentados. A inserção na obra literária de tais "situações eloquentes" [sprechende Situationen], como ele lhes chama, não comprova só a almejada proximidade com o real - mais, ela contribui para a extensão dos modelos de perceção e de conhecimento da realidade através dos sentidos, ou seja, da visão, da audição, do olfato, do tato, e do pensamento do leitor. ${ }^{15}$

11 "Uma história que não tenta convencer-nos de que foi assim, mas antes de que poderia ter sido assim. É o maravilhoso conjuntivo. Maravilhoso, porque nos dá a liberdade para criar uma outra realidade e porque quebra a regra da cronologia." (Ibid., 122; itálicos meus).

${ }^{12}$ Ibid., 142.

${ }^{13}$ Ibid., 139.

${ }^{14}$ Cf. ibid., 106ss.

${ }^{15}$ Ibid., 42, 68 . 
No entanto, a centralidade da presença do real e da linguagem do quotidiano do Homem comum na sua obra não significa - ou não visa - uma diminuição qualitativa e um consequente resvalar para o domínio da trivialidade. Pelo contrário, Uwe Timm descreve mesmo a literatura como o "belo supérfluo" [schöner Überfluss] na época contemporânea e faz questão de sublinhar as diferenças entre a narrativa quotidiana e a narrativa literária, que tem, do ponto de vista formal, um caráter complexo e elaborado. ${ }^{16}$ Timm faz notar também que é na criação de uma distância, de uma estranheza da linguagem do dia-a-dia que reside a diferença essencial entre a verdadeira arte literária e a literatura trivial, a qual se serve da linguagem como simples meio de transporte. ${ }^{17}$

Por conseguinte, o autor tem como desígnio a transformação da vida quotidiana em monumento, ou seja, numa obra de arte literária. ${ }^{18}$ Não tanto por acreditar que a literatura ainda pode transformar o mundo, mas alimentando, pelo menos, a esperança de que ela possa vir a mudar consciências. ${ }^{19}$ Regresso, uma última vez, ao texto do ensaio supramencionado, para citar a súmula final da conceção estético-literária subjacente à obra de Timm que passarei a analisar de seguida:

Vielleicht wäre diese Haltung für den Schriftsteller produktiv: das Alltägliche mit dem Blick des Fremden sehen, nicht mit dem des Touristen, sondern mit dem genauen, forschenden Blick des engagierten Ethnographen. Diese wundersame Reise führt mit der Sprache in das eigene Bewußtsein. Die gewöhnlichen Dinge als ungewöhnlich sehen, der vertrauten Sprache unvertraut begegnen, nahe Menschen - also auch sich selbst - von fern betrachten und darüber erzählen, exakt, ohne Beschönigung, ohne Versöhnung, aber mit Lust, Angst, Wut und Trauer. ${ }^{20}$

${ }^{16}$ Cf. ibid., 8s., 107ss., 111s.

${ }^{17}$ Ibid., 52.

${ }^{18}$ Ibid., 122.

${ }^{19}$ Cf. Kesting/Ruckaberle, op. cit., 12.

20 "Talvez fosse esta a posição produtiva para o escritor: ver o quotidiano com o olhar do estranho, não com o do turista, mas sim com o olhar meticuloso, perscrutador do etnógrafo empenhado. Esta maravilhosa viagem leva-nos através da linguagem à nossa própria consciência. Ver as coisas vulgares como invulgares, encarar a linguagem conhecida com ar desconhecido, observar pessoas que nos são próximas - portanto também a si próprio - à distância e contar acerca disso, de forma exata, sem mitigação, sem conciliação, mas sim com desejo, medo, fúria e pesar." (U. Timm, op. cit., 139; itálicos meus). 
As caraterísticas teórico-poetológicas que acabei de enumerar, ou seja, a conceção da obra literária como construção ficcional (mesmo quando versa temas da historiografia), a importância central da realidade e da linguagem quotidianas, bem como a dimensão lúdica, aliada à exímia arte de narrar, são por demais evidentes na novela histórica A descoberta da salsicha com caril, que, em 1993, catapultou o autor para as luzes da ribalta.

\subsection{A(s) guerra(s) e ofast food alemão: acerca do êxito internacional da novela A descoberta da salsicha com caril (1993) de Uwe Timm}

Com efeito, o enorme êxito desta obra de título curioso, que começou logo por ser saudada, em geral, de modo efusivo pela crítica literária de expressão alemã ${ }^{21}$ e que entretanto conta já com cerca de 250 mil exemplares vendidos, com uma versão em banda desenhada e com uma adaptação cinematográfica, ${ }^{22}$ tal êxito não parece dever-se exclusivamente à polémica matéria histórica abordada, mas sim à forma estimulante como - em conformidade com o ideário estético-literário acima apresentado - essa mesma matéria é selecionada e apresentada ao leitor no texto ficcional. À imagem do que viria a suceder na década seguinte com Am Beispiel meines Bruders [A exemplo do meu irmão] (2003), uma obra autobiográfica igualmente centrada na problemática da "Vergangenheitsbewältigung" [superação do passado nacionalsocialista], ${ }^{23}$ a popularidade da obra novelística galgou as fronteiras dos países de língua alemã e, pela via da tradução, conheceu leitores de outras vinte línguas, incluindo, por exemplo, a chinesa. Infelizmente

${ }^{21}$ Cf. Hans-Georg Schede, Uwe Timm: »Die Entdeckung der Currywurst«, Freising, Stark, 2004, 93ss.

${ }^{22}$ A banda desenhada é da autoria de Isabel Kreitz (Die Entdeckung der Currywurst. Nach einem Roman von Uwe Timm. Mit einer Dokumentation von Frank Giese, Hamburg, Carlsen, 2005 [1. a ed., 1996]), enquanto o filme, realizado por Ulla Wagner e protagonizado pela conceituada atriz Barbara Sukowa, teve a sua estreia em setembro de 2008 (Die Entdeckung der Currywurst. Nach der Novelle von Uwe Timm, DVD, 2009).

${ }^{23}$ Em 2008 o ficcionista retoma a representação literária do nacional-socialismo com a obra Halbschatten [Penumbras], uma biografia romanceada sobre Marga von Etzdorf, uma das primeiras mulheres alemãs a pilotar um avião e a qual teve um destino trágico ainda no dealbar do Terceiro Reich. 
a língua portuguesa não faz parte do vasto leque de traduções da mais conhecida novela de Uwe Timm. De resto, este autor de expressão alemã continua quase inteiramente desconhecido no nosso país, ao contrário de alguns outros colegas seus contemporâneos, como Bernhard Schlink ou Robert Menasse, entre outros, que já viram obras suas editadas na língua de Camões. ${ }^{24}$

Como é bom de ver pelo cotejo das várias versões do paratexto mencionadas na nota anterior, o estranho título da obra começa logo por oferecer dificuldades ao tradutor, dado que se refere a uma especialidade gastronómica alemã que não tem, obviamente, equivalência no contexto sociocultural da língua de chegada - a currywurst. Trata-se de um tipo de comida rápida muito popular, sobretudo no Norte e Centro da Alemanha, que, juntamente com variedades mais tradicionais da salsicha frita ou grelhada, se vende nas típicas barracas e rulotes de comes e bebes que abundam na paisagem urbana de língua alemã. Aliás, este tipo de fast food germânico tornou-se já uma instituição. Prova disso foi a criação, em Berlim, do Museu Alemão da Currywurst, aberto ao público em 2009, em simultâneo com o site na internet. ${ }^{25}$ Mas em 1993, ao defender na sua obra ficcional que a currywurst fora inventada pela senhora Lena Brücker, uma antiga vizinha da sua tia, não em Berlim, mas na cidade de Hamburgo do imediato pós-guerra, Uwe Timm estaria longe de imaginar que havia de desencadear uma autêntica "guerra" sem tréguas em torno da iguaria, cuja patente ficou registada por Herta Heuwer (1913-1999), uma berlinense que reivindicara para si a autoria da receita original, criada em $1949 .{ }^{26}$

${ }^{24}$ Note-se que, apesar da inexistência de uma tradução portuguesa, algumas obras de Timm estão, porém, acessíveis aos leitores portugueses que não dominam o alemão; é também o caso da novela em apreço que conta com uma versão inglesa (The Invention of Curried Sausage. Translated by Leila Vennewitz, New York, New Directions Books), saída logo em 1995 e que subverte um pouco o título original, uma francesa (La decouverte de la saucisse au curry, Roman. Traduit de l'allemand par Bernard Kreiss, Paris, Éditions du Seuil, 1996), que me parece de melhor qualidade, e, em 2003, a tradução espanhola (La invención de la salchicha al curry. Traducción José Pinués, Madrid, Akal Ediciones) e a italiana (La scoperta della currywurst. Trad. Matteo Galli, Florença, Le Lettere).

${ }^{25} \mathrm{Cf}$. http://www.currywurstmuseum.de/en/die-currywurst-hat-ein-museum/ (consultado em 7.9.2012).

${ }^{26}$ Sobre esta polémica, cf. e. o. Mathias Göritz, "Verschärftes Erzählen. Uwe Timms Novelle Die Entdeckung der Currywurst", in: Olaf Kutzmutz (Hrsg.), 
Porém, não é certamente essa "guerra" que nos interessa enquanto leitores. Apenas quero acrescentar a este propósito que, de acordo com a receita tradicional proposta na novela, a currywurst genuína é preparada do seguinte modo: depois de frita, a salsicha de vitela (e não de porco, como em Berlim) é cortada às rodelas e servida num prato de papel descartável, coberta com um molho composto por ketchup e caril, entre outras especiarias. Como se pode também reler na obra em consideração, o petisco germânico tem um sabor invulgar, "süßlichscharf" [picante adocicado] $-{ }^{27}$ para usar a palavra do narrador - e "um aroma" que sugere um ambiente exótico "como que das mil e uma noites" [ein Duft wie aus Tausend und einer Nacht, EC 181]. Aliás,

[...] schon der Name [Currywurst] verrät es, er verbindet das Fernste mit dem Nächsten, den Curry mit der Wurst. Und diese Verbindung, die einer Entdeckung gleichkam, stammt von Frau Brücker und wurde irgendwann Mitte der vierziger Jahre gemacht. (EC 10) ${ }^{28}$

Foram sobretudo estas palavras sugestivas, proferidas no capítulo inicial do texto pelo narrador de primeira pessoa - uma personagem praticamente idêntica ao autor empírico da novela — , que me levaram a preterir o lexema "invenção", escolhido por vários tradutores, e a optar pelo título A descoberta da salsicha com caril; uma obra em que o leitor é levado a acompanhar o narrador anónimo na sua viagem ao passado alemão do final da Segunda Guerra Mundial, determinado a descobrir as origens de uma receita culinária. Mas não se trata de uma viagem meramente turística. Apesar de termos direito a alguns momentos lúdicos, partimos antes numa viagem de reconhecimento e de reflexão sobre aspetos fundamentais relativos a momento fulcral da

Uwe Timm - lauter Lesarten. Beiträge zur Poetik der Gegenwartsliteratur, Wolfenbüttel, Bundesakademie für kulturelle Bildung, 2009, 29-41, e <http:// de.wikipedia.org/wiki/Herta_Heuwer> (consultado em 7.9.2012).

${ }^{27}$ U. Timm, Die Entdeckung der Currywurst, München, Deutscher Taschenbuch Verlag, 2000, 183. Doravante as citações extraídas desta edição da novela em análise serão indicadas, no corpo do texto principal, apenas através das siglas $E C$, seguidas do(s) número(s) da(s) página(s).

28 “[J]á o nome [da salsicha com caril] o denuncia, ele une o mais longínquo com o mais próximo, o caril com a salsicha. E esta união, que equivale a uma descoberta, provém da senhora Brücker e foi feita algures lá por meados dos anos 40." 
História alemã, guiados por um narrador com um olhar estranhante, "o olhar meticuloso, perscrutador do etnógrafo empenhado". ${ }^{29} \mathrm{E}$ a primeira personagem que encontramos nessa peregrinação a alguns lugares da memória coletiva é uma mulher que teve existência real, uma testemunha direta desse tempo histórico - refiro-me a Lena Brücker, a protagonista feminina da novela.

\subsection{A estrutura narrativa e a ação da novela histórica A descoberta da salsicha com caril}

A estratégia narrativa aqui adotada por Uwe Timm está, assim, longe de constituir uma novidade entre a vasta produção de ficção histórica contemporânea. Trata-se, pelo contrário, de uma técnica narrativa bastante comum na chamada metaficção historiográfica, inspirada no modelo histórico-ficcional fundado por Walter Scott. Consiste em apresentar-nos as figuras, os acontecimentos e os espaços historicamente referenciados e - regra geral - bem conservados na memória coletiva, sob a perspetiva menos divulgada, ou mesmo desconhecida do público leitor, que é a perspetiva privada, subjetiva do indivíduo comum que viveu e conviveu com a realidade quotidiana, e ao qual é concedido o protagonismo num universo diegético caraterizado pela hibridez histórico-ficcional. Na presente obra, acresce o facto igualmente "novo" de o protagonismo ser entregue a uma mulher e tanto mais aliciante para o leitor estrangeiro, habituado que está a ouvir a História da Segunda Guerra Mundial narrada através do olhar dos vencedores - a uma mulher de nacionalidade alemã, isto é, pertencente aos grandes derrotados.

A novidade é, de resto, um elemento constitutivo da novela, um género literário que, sobretudo no espaço de língua alemã, se carateriza essencialmente por narrar um acontecimento inaudito, de acordo com a célebre definição de Goethe.$^{30}$ Ora, se a descoberta da salsicha

\footnotetext{
${ }^{29}$ Cf. supra, nota 20.

${ }^{30}$ Este traço constitutivo da novela alemã provém de uma célebre definição do género em apreço, formulada por Goethe, no ano de 1827, em conversa com Johann Peter Eckermann: "[...] was ist eine Novelle anders als eine sich ereignete unerhörte Begebenheit.” [“(...) o que é uma novela senão um acontecimento
} 
com caril - afinal, o móbil central da narração - parece corresponder à caraterística que acabo de enunciar, a verdade é que os críticos literários são quase unânimes em atribuir o caráter inaudito a um determinado aspeto da história de amor vivida por Lena Brücker no final da guerra. Esta relação constitui, aliás, a ação central da obra, repleta de situações e de objetos com dimensão simbólica, e que é marcada por um "ponto de viragem" [Wendepunkt], para referir mais alguns traços típicos da novela alemã. ${ }^{31}$

Quanto ao enredo e à estrutura narrativa da obra em apreço, gostaria de começar por esclarecer a situação de partida: em 1988, o eu-narrador, convicto de que Lena Brücker inventara a receita da deliciosa currywurst, desloca-se, cheio de curiosidade, a um lar de idosos em Hamburgo, onde visita por sete vezes a referida senhora, já octogenária e cega, para ouvi-la contar a história da descoberta daquela iguaria. Enquanto vai tricotando um pulôver, a velha senhora - uma versão idosa de Xerazade - desenovela as histórias pessoais que terá vivido na mesma cidade no fim da Segunda Guerra Mundial, altura em que, com 43 anos de idade, mãe de dois filhos e menosprezada por um marido libertino e envolvido em negócios ilícitos, viveu durante um mês um romance escaldante com um soldado da Marinha, de apenas 24 anos, chamado Hermann Bremer. Este anti-herói torna-se desertor e, por mútuo acordo, permanece escondido em casa dela, pondo em risco a vida de ambos, que ela sustenta sozinha a trabalhar como diretora de uma cantina. Sobretudo para poder manter o idílio amoroso, mas também por ter descoberto que Bremer lhe escondera o fato de ser casado e pai de uma criança, a heroína decide ocultar-lhe o fato de os Alemães terem perdido a guerra, mantendo, assim, o amante como prisioneiro algumas semanas para além da capitulação incondicional da Alemanha nazi. Assim, o verdadeiro acontecimento inaudito da novela parece não ser, afinal, o segredo em torno da descoberta da currywurst - que a senhora Brücker só desvenda no dia da última

inaudito.'] (Johann Peter Eckermann, Gespräche mit Goethe in den letzten Jahren seines Lebens. Neue Ausgabe, hrsg. v. Fritz Bergemann, Wiesbaden, Insel-Verlag, 1955,207 s.).

${ }^{31}$ Sobre as caraterísticas típicas da novela presentes na obra em apreço, cf. e. o. Tina Rausch, "Uwe Timm: Die Entdeckung der Currywurst. Ein Interpretationsansatz", 2004, 4. <http://www.dtv.de/_pdf/lehrermodell/12839.pdf> (consultado em 10.5.2011), H.-G. Schede, op. cit., 82ss., e Mathias Göritz, op. cit., 29ss. 
visita do eu-narrador - , mas sim a mentira piedosa que possibilita à mulher emancipada o prolongamento de uma história de amor em tempos sombrios.

Antes de me debruçar sobre o texto da novela, só mais uma palavra acerca da estrutura narrativa: através da técnica da narrativa enquadrada, outra caraterística típica do género novelístico, constituem-se dois estratos históricos ou espácio-temporais distintos, os quais facultam ao leitor um olhar distanciado, porque filtrado a partir do presente histórico da narração (o ano de 1988) - quer pela narração, por vezes nostálgica, da velha senhora quer pelo discurso crítico e mais objetivo do eu-narrador - , um olhar distanciado do que poderia ter acontecido no quotidiano daquele passado histórico bastante sombrio (abril/maio de 1945). ${ }^{32}$ No entanto, a alternância frequente entre os dois planos histórico-cronológicos leva a que a voz da heroína do passado, com 43 anos, se misture e confunda, sem qualquer mediação narrativa nem qualquer sinalização gráfica, com a voz da octogenária, conferindo, em determinados momentos, um cunho mais subjetivo à reconstrução do passado histórico e biográfico da protagonista.

\subsection{Principais contornos da crise e catástrofe alemã na novela A descoberta da salsicha com caril}

\section{O pano de fundo histórico-político e social}

Na verdade, é a figura do narrador - um alter ego de Uwe Timm - que seleciona e configura as sete partes da história contada, de forma desordenada, por Lena Brücker no todo coerente que constitui o mundo histórico-ficcional da novela. A primeira referência ao pano de fundo histórico-político é, consequentemente, feita por ele:

Ich lasse die Geschichte am 29. April 1945, an einem Sonntag beginnen.

Das Wetter in Hamburg: überwiegend stark bewölkt, trocken. Temperatur zwischen 1,9 und 8,9 Grad.

${ }^{32}$ Sobre os aspetos narratológicos da novela, veja-se Rausch, op. cit., 5, e H.G. Schede, op. cit., 36ss. 
2.00: Hitlers Trauung mit Eva Braun. Trauzeugen sind Bormann und Goebbels.

3.30: Hitler diktiert sein politisches Testament. Großadmiral Dönitz soll seine Nachfolge als Staatsoberhaupt und Oberbefehlshaber antreten.

5.30: Die Engländer gehen in Artlenburg über die Elbe.

Hamburg soll als Festung bis zum letzten Mann verteidigt werden. Barrikaden werden gebaut, der Volkssturm wird aufgerufen, der Heldenklau geht durch die Krankenhäuser, das letzte, das allerletzte, das allerallerletzte Aufgebot wird an die Front geworfen, so auch der Bootsmann Bremer, der in Oslo im Stab des Admirals die Seekartenkammer geleitet hatte. $(E C \text { 16s. })^{33}$

Neste passo, com uma dimensão meta-reflexiva caraterística da ficção histórica pós-modernista, o narrador mostra o ofício do escritor na tarefa de seleção e configuração dos dados políticos e meteorológicos de cariz factual, assumindo, deste modo, o caráter construído da narrativa. Ato contínuo, ele abandona o papel de mero cronista histórico e coloca as vestes de ficcionista, quando introduz no discurso historiográfico a figura fictícia, ou ficcionalizada, do soldado da Marinha que, por mero acaso, estará prestes a encontrar Lena Brücker, com quem irá protagonizar a relação amorosa que vai fazer andar a ação central da novela. No decurso da exposição narrativa, o leitor fica a conhecer, de igual modo, as primeiras coordenadas espácio-temporais do acontecer. O cenário é bem conhecido: encontramo-nos na fase final da Segunda Grande Guerra, coincidente com a derrocada do famigerado Terceiro Reich, mais concretamente numa das principais cidades

33 "Vou começar a história a 29 de abril de 1945, a um domingo. O tempo em Hamburgo: geralmente muito nublado, seco. Temperatura entre 1,9 e 8,9 graus.

2.00: Casamento de Hitler com Eva Braun. Os padrinhos são Bormann e Goebbels.

3.30: Hitler dita o seu testamento político. O Almirante Dönitz deverá assumir a sucessão como Chefe de Estado e Comandante Supremo das Forças Armadas.

5.30: Os Ingleses atravessam o Elba em Artlenburg.

Hamburgo será defendida como uma fortaleza até ao último homem. São erguidas barricadas, é mobilizado o Volkssturm, o recrutamento de heróis inclui os hospitais, as últimas, as últimas das últimas das últimas reservas são atiradas para a frente de batalha, incluindo o contramestre Bremer, o qual dirigira em Oslo a sala de cartografia marítima do Estado Maior da Armada." 
alemãs, a qual está à beira de ser conquistada pelos Aliados, que dão, assim, mais um passo de gigante rumo à vitória final.

\section{O primeiro encontro entre Lena Brücker e Hermann Bremer no cinema e no bunker (29 de abril de 1945)}

$\mathrm{Na}$ cena do primeiro encontro entre o par amoroso, que acaba de se conhecer na fila de entrada para o cinema e assiste à projeção de um filme propagandístico, enfeudado nos ideais nacional-socialistas da superioridade da raça ariana, traz à memória dos Alemães as experiências traumáticas de uma dantesca "tempestade de fogo" [Feuersturm] que havia assolado a cidade hanseática e a respetiva população, no verão de 1943, quando fora alvo de um dos mais violentos, e eficazes, ataques aéreos das potências aliadas. ${ }^{34}$ Os bombardeamentos intensos por parte da Força Aérea anglo-americana haviam levado à destruição maciça de Hamburgo, deixando a cidade em escombros e cinzas, e provocando a morte a quase 40.000 civis, um cenário que ameaça repetir-se agora que os Ingleses se aproximam e têm já sob ataque a cidade do Elba: ${ }^{35}$

Noch während der Vorschau [...] begannen draußen die Luftschutzsirenen zu heulen. Das Saallicht ging an, flackerte, fiel aus. Licht von Taschenlampen. Die Zuschauer drängten aus den beiden Saaltüren, liefen in Richtung auf den großen Bunker an der Reeperbahn. In einen Großbunker wollte sie auf keinen Fall. Lieber in irgendeinen Luftschutzkeller. Einer dieser großen Bunker hatte nämlich neulich einen Volltreffer vor die Tür bekommen. Ein Feuersturm war durch den Bunker gegangen. Später sah man die Menschen an den Leitungen hängen, verkohlt und klein

${ }^{34} \mathrm{Cf}$. <http://www.ndr.de/land_leute/norddeutsche_geschichte/dossierfeuersturm100.html > (consultado em 7.9.2012).

${ }^{35}$ De entre a bibliografia historiográfica sobre esta matéria, destaco os seguintes estudos em língua alemã: Hans Brunswig, Feuersturm über Hamburg: Die Luftangriffe auf Hamburg im 2. Weltkrieg und ihre Folgen, Stuttgart, Motorbuch, 2003; Christian Hanke et al., Hamburg im Bombenkrieg 1940-1945: Das Schicksal einer Stadt, Hamburg, Medien-Verlag Schubert, ${ }^{32001}$; Uwe Bahnsen/Kerstin von Stürmer, Die Stadt, die sterben sollte - Hamburg im Bombenkrieg, Juli 1943, Hamburg, Convent, 2004; U. Bahnsen/K. v. Stürmer, Die Stadt, die leben wollte Hamburg und die Stunde Null, Hamburg, Convent, 2004. 
wie Puppen. Lena Brücker lief zu einem Wohnhaus, folgte dem weißen Pfeil: Luftschutzraum, hinter ihr her Bremer. (EC 20s.) ${ }^{36}$

Com a inclusão, na novela, do bombardeamento da cidade de Hamburgo e, consequentemente, do tema do sofrimento da população alemã na fase terminal da guerra, Timm é um dos primeiros autores a quebrar um tabu na literatura alemã após 1945, uma situação que, só no final dos anos 90, viria a ser abertamente denunciada por W. G. Sebald, num polémico conjunto de conferências proferidas na Universidade de Zurique e publicadas sob o título Luftkrieg und Literatur (Guerra aérea e literatura, 1999).

\section{A resistência ao regime nacional-socialista}

Cessado o ataque, a que os protagonistas escapam ilesos, Lena Brücker dá abrigo e jantar ao jovem contramestre, eles apaixonam-se, passam a noite juntos e Bremer, temendo as agruras da guerra em alto mar, acaba por desistir de se apresentar ao serviço na manhã seguinte, incorrendo no crime capital de deserção. No entanto, a ajuda prestada pela heroína ao soldado alemão, que renuncia a lutar pela pátria nazi, não se deve a razões amorosas, como confessa ao narratário, na sua linguagem tingida pelo dialeto de Hamburgo:

Das hatte nix mit Sympathie zu tun. Hätte jedem geholfen, der nicht mehr mitmachen wollte. Einfach versteckt. Is ja das Kleine, was die Großen stolpern läßt. Nur müssen wir viele sein, damit die auch fallen.

36 “Ainda durante os documentários [...] começaram a tocar lá fora as sirenes antiaéreas. As luzes da sala acenderam-se, tremeluziram, apagaram-se. Luzes de pilhas. Os espetadores apinhavam-se junto às portas de saída da sala, corriam em direção ao grande bunker da Reeperbahn. Num bunker dos grandes é que ela nem pensava em meter-se. Era preferível um qualquer abrigo numa cave. É que ainda pouco antes um desses bunkers grandes tinha sido atingido em cheio, mesmo na porta de entrada. O interior fora varrido por uma tempestade de fogo. Mais tarde viam-se as pessoas penduradas nos canos, carbonizadas e tão pequenas que pareciam bonecos. Lena Brücker correu para uma casa, seguindo a seta branca: abrigo antiaéreo, com Bremer no seu encalço." 
Deine Großmutter, die war mutig. Die hat mal eingegriffen. Kennste die Geschichte mit m Knüppel? (EC 102) ${ }^{37}$

A cumplicidade com o desertor é, pois, encarada como um ato de oposição individual ao regime criminoso liderado por Hitler, idênticos a inúmeras outras ações isoladas que parecem ter sido praticadas durante o período de terror nazi. O motivo da resistência, sob a forma de atos ocasionais que, sem emperrar verdadeiramente o funcionamento do sistema, provocam desconforto e irritação a figuras e estruturas institucionais alinhadas com o poder político do Terceiro Reich, ressurge pontualmente no texto da novela, como que refutando a tese da culpa coletiva atribuída aos Alemães no rescaldo do maior conflito bélico da História. A referência ao episódio burlesco, inúmeras vezes recontado no seio da família, em que a avó do eu-narrador (tal como a do próprio autor, diga-se), num ato de coragem exemplar, rouba o cacete a um soldado das SS para evitar o espancamento de dois prisioneiros russos, é bem ilustrativa do que acabo de mencionar e comprova também a já aludida interdependência ou miscigenação, na obra ficcional de Uwe Timm, de aspetos relativos à História coletiva com elementos histórico-biográficos.

Em matéria de resistência por parte de indivíduos comuns, gostaria de referir também o caso de Holzinger, o cozinheiro que fora despromovido e relegado para a cantina onde trabalha a protagonista, devido a repetidos, mas incomprováveis atos de sabotagem culinária, provocando, inclusive a dirigentes nazis, ataques de cólicas e de vómitos por ocasião dos festejos de vitórias militares do Terceiro Reich na fase inicial da guerra (cf. EC 52s.). Uma prática arriscada, mas da qual não abdica até ao dia da capitulação incondicional da cidade de Hamburgo. A verdade é que, embora tais figuras corajosas, capazes de pôr em prática atos subversivos não raro com contornos cómicos, suscitem facilmente a empatia do leitor, elas acabam por revelar-se absolutamente insuficientes no seio do hiper-vigiado Estado totalitário,

37 "Não tinha nada a ver com simpatia. Tinha ajudado qualquer um que quisesse desistir de participar naquilo. Tinha-o escondido, sem mais. O pequeno é que faz tropeçar o grande. Temos de ser é muitos para que eles caiam mesmo. A tua avó, essa é que era valente. Uma vez ela interveio. Conheces a história do cacete?" 
o qual só foi possível depor a partir do exterior, e através da força conjunta e impiedosa dos Aliados. ${ }^{38}$

\section{Cúmplices e culpados do regime nacional-socialista}

O contraponto aos referidos atos de resistência individuais e esporádicos, no fundo tão ineficazes quanto as várias ações conspirativas de desfecho trágico, planeadas e executadas para derrubar Hitler (como a "Operação Valquíria", por exemplo), encontram-se noutro tipo de atitudes, protagonizadas por personagens que, de uma forma mais ou menos declarada, colaboram com o Estado nacional-socialista. Reporto-me, em primeiro lugar, ao senhor Lammers, assumido simpatizante do regime, que tem a seu cargo a vigilância do prédio em que mora Lena Brücker, e chega a provocar o pânico a Bremer quando só por um triz não vem a ser descoberto, mas - como o eu-narrador vem a descobrir através da consulta dos arquivos respeitantes à polícia política do Terceiro Reich - até é considerado como um informador "inadequado". Veja-se porquê: "Eine Eintragung der Gestapo über Lammers: »Überzeugter Nationalsozialist. Lehnt aber Berichte über Mitbewohner ab. Ungeeignet! «" (EC 121). ${ }^{39}$

Incapaz de conviver com a humilhação da derrota, segue o exemplo do Führer, envergando a farda e cometendo suicídio, logo após a capitulação da cidade. Outra figura pertencente ao imenso rol de carrascos ou culpados que pertenciam a instituições oficiais do regime é a senhora Eckleben, também vizinha da protagonista. Boa dissimuladora, ninguém parece ter suspeitado da sua verdadeira identidade de denunciante. Por meio de um relatório, entregara às autoridades um vizinho contestatário e nem Lena Brücker pudera algum dia desconfiar das informações que a vizinha veio a fornecer à Gestapo a seu próprio respeito:

${ }^{38}$ A respeito da problemática da resistência na obra de Uwe Timm, leia-se o artigo de Ulrich Simon, "Die Leistung des Scheiterns. Widerstehen als Thema und als Problem in Uwe Timms Texten”, in: Erinnern, Vergessen, Erzählen. Beiträge zum Werk Uwe Timms, Beiträge zum Werk Uwe Timms. Hrsg. v. Friedhelm Marx unter Mitarbeit v. Stephanie Catani u. Julia Schöll, Göttingen, Wallstein Verlag, 2007, 203-222.

39 "Um registo da Gestapo sobre Lammers: «Nacional-socialista convicto. Mas recusa fazer relatórios sobre os vizinhos do prédio. Inadequado!»" 
"L. Brücker hetzt nicht offen, macht aber oft zersetzende kritische Bemerkungen. Beispielsweise zur Versorgungslage bei den Brennmitteln. B: Ich glaube nicht, daß der Führer so kalte Füße hat wie ich. (Umstehende lachen.) Oder: Die Juden sind auch Menschen. Oder: Das Volk liebt den Führer. Wenn ich das schon hör. Ich liebe meine Kinder. Und früher meinen Mann. Ich weiß, wohin das führt. 15.2.43" (EC 120) $)^{40}$

O ficheiro da Gestapo é mais um material autêntico com valor histórico-documental de que o ficcionista se apropria para colocar ao serviço da caraterização político-ideológica das figuras no mundo histórico-ficcional da novela. O documento diz-nos tanto acerca do apego da denunciante aos ideais nazis como sobre o distanciamento crítico da heroína em relação aos mesmos, o que leva esta última a conquistar a simpatia do leitor. Resta ainda dizer que Frau Eckleben, à semelhança do doutor Fröhlich, uma outra figura filiada na NSDAP, não só sobrevive como rapidamente coloca a máscara de democrata, contornando o processo de desnazificação, de modo a integrar-se comodamente na realidade social e política do pós-guerra.

\section{As notícias da morte de Hitler e da capitulação de Hamburgo (2 de maio de 1945)}

A novela histórica, cuja ação decorre no término da guerra em Hamburgo, não podia deixar de integrar o relato de aspetos relacionados com a conquista da cidade pelas tropas britânicas. Esses acontecimentos, de consequências catastróficas para a população civil alemã, vêm relatados no início do quarto capítulo, precedidos da notícia da morte de Hitler, transmitida via rádio, comprovando à saciedade a persistência grotesca na manipulação nacional-socialista dos órgãos de

40 “ «L. Brücker não ataca abertamente, mas faz com frequência observações críticas de caráter subversivo. Por exemplo, sobre o fornecimento de combustíveis. B: Não acredito que o Führer tenha os pés tão frios como eu. (Risadas das pessoas à volta.) Ou: Os judeus também são seres humanos. Ou: O povo ama o Führer. Quando eu ouço uma coisa destas. Eu amo é os meus filhos. E dantes o meu marido. Eu sei aonde é que isso nos leva. 15.2.43.»” 
comunicação social: “Am 1. Mai meldete der Reichssender Hamburg: Der Führer Adolf Hitler ist heute nachmittag auf seinem Befehlsstand in der Reichskanzlei, bis zum letzten Atemzug gegen den Bolchevismus kämpfend, für Deutschland gefallen.” (EC 86).$^{41}$

Em especial para o leitor contemporâneo, é gritante o contraste entre a alegada morte heróica do Führer, lutando honrosamente contra o inimigo, tal como é anunciada através do comunicado oficial, e os acontecimentos históricos que terão efetivamente ocorrido no bunker berlinense a 30 de abril de 1945. Parece evidente que o autor joga aqui com o conhecimento que a generalidade dos leitores possuem acerca da morte de Hitler para ilustrar o modo como o Almirante Dönitz se mostra fiel ao antecessor no comando da Alemanha moribunda, quando se preocupa com deturpar acontecimentos, com negar evidências ou atos consumados, nomeadamente ocultando, sob a capa de um ato heróico, o suicídio cobarde do ditador nazi.

Infelizmente, falta-me o espaço para citar e comentar criticamente a forma como o texto desmascara a hipocrisia e a falsidade do poder político central, agora comandado por Dönitz, quando, após a capitulação de Hamburgo e na iminência da inevitável derrocada final do Terceiro Reich, continua, de forma desesperada e mesmo patética, a apelar de forma veemente à resistência através das armas, sem respeito pelos seres humanos, sejam eles soldados inimigos ou mesmo cidadãos de Hamburgo. No entanto, o governador da cidade refuta as ordens impostas e aceita a derrota, enquanto a população as ignora ou escuta, com perplexidade, um discurso radiofónico em que um dirigente nacional-socialista reconhece agora o absurdo e a desumanidade da guerra, e lamenta a crueldade dos Aliados na destruição de cidades e no massacre de populações, esboçando um desajeitado discurso de auto-vitimização, enquanto Lena Brücker despe a bata e sai à rua para anunciar às pessoas com que se cruza que a guerra acabou (cf. EC 87s.).

41 "No dia 1 de maio a emissora do Reich em Hamburgo anunciou: Hoje à tarde o Führer Adolf Hitler caiu pela Alemanha, no seu posto de comando da chancelaria do Reich, lutando até ao último suspiro contra o bolchevismo." 


\section{A realidade do Holocausto e o fim da relação amorosa (25 de maio de 1945)}

É um facto que tenho vindo a relegar para segundo plano não apenas a salsicha com caril como também a história de amor entre a funcionária da cantina e o soldado desertor, em detrimento da matéria historiográfica inserida na sintagmática narrativa. Contudo, isto não acontece por acaso, dado que as figuras e os acontecimentos históricos que vão circulando no universo diegético, tal como na vida real, tendem a intrometer-se no quotidiano das pessoas. É o que acontece aos protagonistas da novela, cuja relação, depois de uma briga seguida de uma breve peripécia, se torna cada vez mais tensa e caminha já para o desenlace: enquanto Bremer, qual prisioneiro, desespera pela obtenção de notícias sobre a evolução de uma guerra que, a seus olhos, parece não mais acabar; já Lena Brücker, como não quer perder o amante, sente crescentes dificuldades em negar-lhe a existência de jornais e de rádios, em esconder-lhe o facto de a guerra ter terminado já há semanas. Até que um dia a inaudita História coletiva alemã põe mesmo fim à inaudita história de amor, e de forma devastadora.

A 27 de maio de 1945, Lena chega a casa de mau humor, depois de ter visto, estampadas nos jornais, fotografias que ilustram o horror dos campos de concentração e de extermínio libertados pelos Aliados:

Dachau, Buchenwald, Bergen-Belsen. Waggons voller Leichen, nur noch mit Haut überzogene Skelette. [...]

Menschen, Juden, sollen, sagte sie zu Bremer und zwang sich ruhig zu bleiben, vergast und dann verbrannt worden sein. Unvorstellbare Dinge sind passiert. Es soll Fabriken des Todes gegeben haben.

Märchen, sagte Bremer, alles Quatsch. Feindpropaganda. Wer hat ein Interesse, solche Gerüchte in die Welt zu setzen? Der Russe. Und dann sagte er etwas, was Lena Brücker aus der Fassung brachte. Sie hatte aufgehört zu stricken, das Strickzeug im Schoß, sah ein wenig über mich hinweg, schüttelte den Kopf: Ist schon Breslau entsetzt, hat er gefragt.

Da, es war das erste, das einzige Mal, schrie sie ihn an: Nein. Die Stadt ist im Arsch! Schon längst. Platt. Verstehste. Nix. Gauleiter Handke abgehauen. Mit nem Fieseler Storch. Ein großes Schwein, wie dieser Dr. Fröhlich ein kleines Schwein ist. Alles Schweine. Jeder in Uniform is $\mathrm{n}$ Schwein. Du mit deinem dämlichen Kriegsspiel. Der Krieg ist aus. 
Verstehste, aus. Längst. Aus. Vorbei. Futschikato. Wir haben ihn verloren, total. Gott sei Dank. (EC 146s. $)^{42}$

A revelação da verdade sobre o horror do Holocausto, escrupulosamente posto em prática de acordo com o plano de "solução final para a questão judaica" ("Endlösung der Judenfrage") decidido na Wannseekonferenz, em 1942, leva a protagonista a tomar consciência plena da dimensão das atrocidades cometidas pelo regime. Ao contrário do soldado da Marinha desertor, que, alheado da realidade, se havia entretido a imaginar estratégias militares que conduzissem a uma aliança germano-britânica para derrotar o inimigo comunista, e prefere acreditar que o genocídio de mais de cinco milhões de judeus e meio milhão de ciganos - para não mencionar outro tipo de vítimas dos campos de extermínio, dispersos pelo vasto território do Terceiro Reich - , Bremer prefere acreditar que o Holocausto não passa de uma ilusória campanha de difamação por parte dos soviéticos.

A indignação de Lena Brücker com a reação do amante é tão profunda que a revelação da outra verdade ocultada, ou seja, a mentira íntima sobre a continuidade da guerra, torna intransponível o fosso cavado entre ambos pela catastrófica realidade histórica da Alemanha nacional-socialista. Lena sai de casa para deambular errática pelas ruas bombardeadas, fazendo um mea culpa pela passividade demonstrada quando, um dia, se limitara a assistir à deportação da senhora Levinson,

42 "Dachau, Buchenwald, Bergen-Belsen. Vagões repletos de cadáveres, esqueletos cobertos já só com a pele. [...]

Pessoas, judeus, terão sido, disse a Bremer e fez um esforço enorme para manter a calma, gaseados e depois queimados. Passaram-se coisas inimagináveis. Parece que havia fábricas de morte.

Contos de fadas, disse Bremer, tudo disparates. Propaganda inimiga. Quem é que tem interesse em pôr esses boatos a circular? Os Russos. E depois ele disse uma coisa que levou Lena Brücker a perder a calma. Ela parara de tricotar, o tricô no regaço, olhou um pouco por cima de mim, abanou a cabeça: Breslau já foi libertada, perguntou ele.

Então, foi a primeira e única vez, berrou com ele: Não. A cidade foi para o diabo! Há muito tempo já. Esmagada. 'tás a entender. Nada. O Gauleiter Handke pôs-se a andar. Num avião, um Fieseler Storch. Um grande porco, do mesmo modo que aquele dr. Fröhlich é um pequeno porco. Todos uns porcos. Todos os que usam farda são uns porcos. Tu e o teu estúpido jogo de guerra. A guerra acabou. 'tás a entender, acabou. Há tempo. Acabou. Ponto final. Finito. Nós perdemo-la, totalmente. Graças a Deus." 
uma vizinha judia. E, quando a heroína regressa a casa, é inevitável, Bremer já lá não está.

\section{O “milagre” de Lena Brücker no pós-guerra}

A falta de espaço obriga-me a deixar a abordagem da realidade do pós-guerra para uma outra oportunidade. Ainda assim, não posso deixar de referir que, pelo menos no mundo histórico-ficcional criado por Uwe Timm, e que só o leitor ingénuo terá tomado como real, Lena Brücker, no meio das privações extremas e do mercado negro instalado por entre os escombros da Segunda Guerra Mundial, vem, de facto, a descobrir uma receita milagrosa que lhe garante a sobrevivência no pós-guerra, e como mulher emancipada. O marido, um incorrigível mulherengo, ocioso e machista, regressa a casa, mas acaba rapidamente expulso. A sua barraquinha de salsichas ganha fama e prospera, graças à salsicha com caril, que se afigura, no final, como o símbolo central da novela, apontando o caminho do Wiederaufbau, da reconstrução da República Federal da Alemanha no pós-guerra, mas sugerindo, através da figura de Lena Brücker, uma reconstrução alternativa, baseada em novos valores que rompam efetivamente com o passado, o que, a meu ver, deixa uma crítica implícita ao processo de reconstrução da sociedade alemã ocidental após $1945 .{ }^{43}$

\section{Balanço da (re)construção histórico-ficcional da derrocada do Terceiro Reich}

Em jeito de balanço da (re)construção histórico-ficcional da derrocada do Terceiro Reich na novela A descoberta da salsicha com caril de Uwe Timm, gostaria de salientar que a novidade do olhar retrospetivo lançado sobre a Alemanha na hora da derrota militar, e do regime nacional-socialista, às mãos das três potências aliadas (Grã-Bretanha, EUA e União Soviética) reside, fundamentalmente, no seu caráter

${ }^{43}$ Cf. S. Taberner, "Literature in the West”, in: S. T. (ed.), German Literature of the 1990s and Beyond. Normalization and the Berlin Republic, New York/Suffolk, Camden House, 2005, 77s. 
diferenciado. De facto, ao retratar na novela histórica um conjunto diversificado de figuras, que vão desde os carrascos e outros culpados, cúmplices ou denunciantes, até às vítimas de perseguição político-ideológica e do Holocausto, passando por resistentes audaciosos e críticos ou oposicionistas mais reservados, Timm oferece ao leitor uma perspetiva, efetivamente, mais realista dos Alemães que viveram o período histórico em consideração. Além disso, mostra igualmente o sofrimento por que passou a população civil durante determinadas fases da maior crise e catástrofe da História alemã, nomeadamente aquando dos ataques aéreos sobre a cidade de Hamburgo. E, dado que não só está longe de esboçar qualquer tentativa de branqueamento do caráter criminoso do regime nazi, como antes denuncia claramente as atrocidades cometidas pelos nacional-socialistas, o autor evita, assim, um tratamento simplista da história dos vencidos da Segunda Guerra Mundial, porventura mais próximo de mundivisões maniqueístas e/ou de posições politicamente corretas.

Haveria, certamente, muito mais a dizer a este respeito, bem como acerca dos aspetos narratológicos, ou - para voltar ao título da obra - sobre a forma exata como Lena Brücker se reergueu no meio dos escombros e, no outono de 1947, terá descoberto, por mero acaso, o segredo da salsicha com caril, uma descoberta "picante adocicada" ("süßlichscharf", EC 183) que, por alguma razão, está intimamente ligada à história de amor que ela viveu com Hermann Bremer no mundo ficcional da novela. Contudo, tais desideratos terão de aguardar por nova oportunidade. Entretanto, quem desejar conhecer o verdadeiro desfecho d'A descoberta da salsicha com caril só terá de ler a obra de Uwe Timm, tendo à sua disposição versões em várias línguas. ${ }^{44}$

${ }^{44}$ Cf. supra, nota 23. 